\title{
Novel protein extraction approach using micro- sized chamber for evaluation of proteins eluted from formalin-fixed paraffin-embedded tissue sections
}

\author{
Keiichi Hatakeyama ${ }^{1 *}$, Kanako Wakabayashi-Nakao', Yutaka Aoki ${ }^{2}$, Shun-ichiro Ogura ${ }^{3}$, Ken Yamaguchi', \\ Takashi Nakajima ${ }^{5}$, Taka-Aki Sato ${ }^{2}$, Tohru Mochizuki ${ }^{1}$ and Isamu Hayashi ${ }^{5}$
}

\begin{abstract}
We describe a novel antigen-retrieval method using a micro-sized chamber for mass spectrometry (MS) analysis to identify proteins that are preferentially eluted from formalin-fixed paraffin-embedded (FFPE) samples. This approach revealed that heat-induced antigen retrieval (HIAR) from an FFPE sample fixed on a glass slide not only improves protein identification, but also facilitates preferential elution of protein subsets corresponding to the properties of antigen-retrieval buffers. Our approach may contribute to an understanding of the mechanism of HIAR.
\end{abstract}

Keywords: Antigen retrieval, Colon adenoma, Colon cancer, FFPE tissue, Gastric cancer, Heat-induced antigen retrieval, Mass spectrometry, Micro-sized chamber

\section{Background}

The standard method for storing clinical specimens in hospital tissue banks is in the form of formalin-fixed paraffin-embedded (FFPE) tissue samples, and these are both abundant and widely available for pathological diagnosis worldwide. Recently, FFPE tissue samples have been subjected to mass spectrometry (MS)-based proteomic analysis [1-4], and several studies in FFPE samples employed heat-induced antigen retrieval (HIAR) to improve protein identification [1,4-12]. These investigations have demonstrated the similarity of protein identification between FFPE and fresh/frozen tissue samples [4,9,12-15]. Thus, FFPE tissues are now considered an alternative to fresh/ frozen tissues for protein biomarker discovery.

Although several groups have reported the equivalence of proteomes derived from fresh/frozen and FFPE samples, the mechanism of protein extraction by HIAR is not entirely understood. HIAR was originally developed to improve the sensitivity of immunohistochemical methods $[16,17]$, and is used to unmask epitopes in FFPE samples

\footnotetext{
* Correspondence: k.hatakeyama@scchr.jp

'Medical Genetics Division, Shizuoka Cancer Center Research Institute, 1007

Shimonagakubo, Nagaizumi-cho, Sunto-gun, Shizuoka 411-8777, Japan

Full list of author information is available at the end of the article
}

$[18,19]$. Recent MS imaging of FFPE tissues suggests that HIAR treatment also increases accessibility of proteins to trypsin $[6,20]$. However, these studies focused only on the retrieved proteins remaining in the FFPE tissue sections. Chu et al. have shown that HIAR treatment facilitates partial release of macromolecules (polypeptides, nucleic acids, and lipids) from FFPE tissues fixed on a glass slide [21]. In their study, the proteins released from FFPE samples by HIAR were not investigated or characterized by MS analysis.

In this study, we report a novel antigen-retrieval method using a micro-sized chamber for identifying proteins eluted from FFPE tissue samples. FFPE colon cancer tissue sections fixed on a glass slide were treated by HIAR in a fabricated chamber. The method yielded improved protein identification compared to untreated samples, as assessed by MS/MS analysis using a nano-flow LC-ESI linear ion trap (LIT)-TOF mass spectrometer. Our new proteomic approach allows identification and characterization of the proteins eluted from FFPE tissues fixed on the glass slide. We suggest that this antigen-retrieval method can lead to a more in-depth understanding of the mechanisms of HIAR. 


\section{Methods}

\section{Tissue fixation}

Tissue samples were prepared from surgically removed human colon and gastric cancer and colon adenoma specimens, in accordance with the standard local therapeutic protocol. Samples (approximately $2 \mathrm{~g}$ ) were fixed in $10 \%$ buffered formalin for $48 \mathrm{~h}$ at room temperature, dehydrated with ethyl alcohol, and embedded in paraffin. Paraffin blocks were stored in the dark at room temperature for 2 years.

\section{HIAR using micro-sized chamber}

The workflow for protein retrieval and identification in FFPE samples is shown in Figure 1. Sections (3- $\mu$ m thick; approximate area, $15 \times 20 \mathrm{~mm}$ ) were cut and transferred onto a glass slide. Sections were deparaffinized in xylene and rehydrated through a series of alcohol treatment. For HIAR, the deparaffinized sections were incubated in $120 \mu \mathrm{l}$ of antigen-retrieval buffer $(50 \mathrm{mM}$ Tris- $\mathrm{HCl}, \mathrm{pH}$ 10.0 , and $0.1 \% n$-octyl- $\beta$-D-glucoside) in a micro-sized chamber (Frame-Seal Incubation Chambers for In Situ PCR and Hybridization, $17 \mathrm{~mm} \times 28 \mathrm{~mm} \times 250 \mu \mathrm{m}$; BioRad Laboratories, Hercules, CA) or in $30 \mathrm{ml}$ of antigenretrieval buffer in an incubation vessel (diameter, $66 \mathrm{~mm}$ $\times 101 \mathrm{~mm}$; As One, Osaka, Japan). Chambers were heated to $90-110^{\circ} \mathrm{C}$ for $10 \mathrm{~min}$ in an autoclave. After HIAR in the micro-sized chamber, we collected only the supernatant from the chamber by using a pipette (Figure 2). The collected supernatants were then concentrated using a SpeedVac (Thermo Fisher Scientific, Waltham, MA). After HIAR in the incubation vessel, the collected antigenretrieval buffer (25-30 $\mathrm{ml})$ was concentrated using an

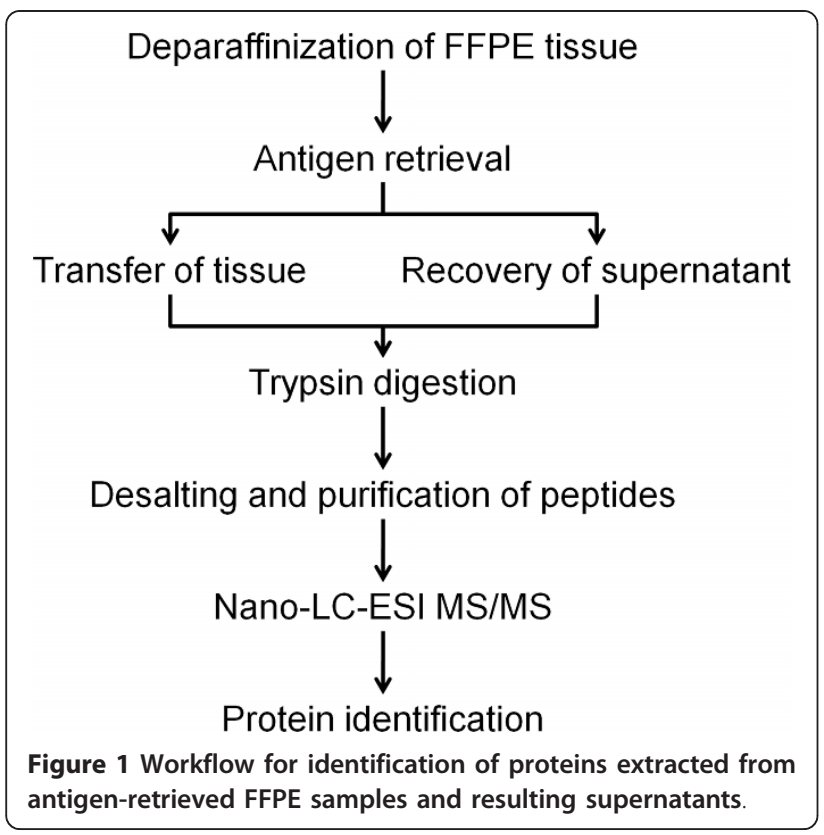

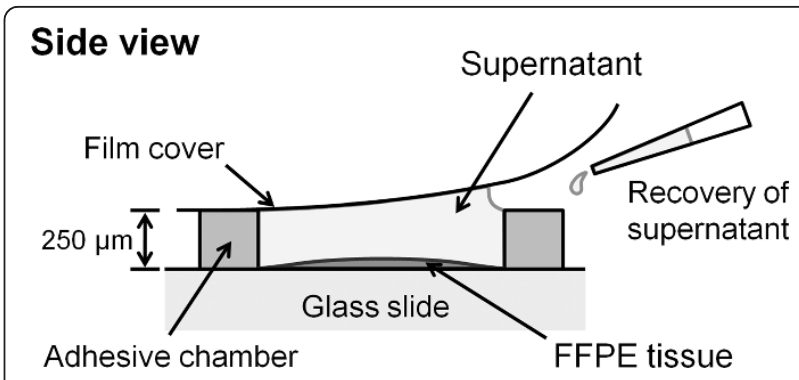

Figure 2 Illustration of the recovery process for antigenretrieval buffer in the micro-sized chamber. The antigen-retrieval buffer was added to the micro-sized chamber adhered to the slide, and then sealed with a film cover. After HIAR, the antigen-retrieval buffer (supernatant) was recovered with a pipette.

Amicon Ultra-15 Centrifugal Filter Unit with an Ultracel3 membrane (Millipore, Billerica, MA). We chose this method because precipitated salts from the antigen-retrieval buffer can influence subsequent processes such as trypsinization and MS analysis. The above-described process was repeated twice by using the same paraffin block.

\section{Trypsin digestion and peptide extraction}

FFPE samples with/without HIAR were removed from the glass slide and immersed in $50 \mathrm{mM}$ ammonium bicarbonate. These samples were trypsinized at a final enzyme concentration of $25 \mu \mathrm{g} / \mathrm{ml}$ at $37^{\circ} \mathrm{C}$ for $18 \mathrm{~h}$. The tryptic digests were twice desalted with $\operatorname{ZipTip}_{\mu-\mathrm{C} 18}$ (Millipore). The samples were individually concentrated using the SpeedVac, and reconstituted in $0.1 \%$ formic acid.

\section{LC-MS/MS}

MS/MS analysis of samples was carried out on a nanoflow LC-ESI LIT-TOF mass spectrometer (NanoFrontier L; Hitachi High-Technologies, Tokyo, Japan) as previously described [22,23]. The dissolved digests were injected into a $0.05 \mathrm{~mm} \times 150 \mathrm{~mm}$ MonoCap for Fast-flow (GL Science, Tokyo, Japan) via a $0.05 \mathrm{~mm} \times 150 \mathrm{~mm}$ Monolith Trap C18-50-150 (Hitachi High-Technologies), and the peptides were separated using solvent A $(0.1 \%$ formic acid and $2 \%$ acetonitrile in water)/solvent $\mathrm{B}(0.1 \%$ formic acid and $2 \%$ water in acetonitrile) gradient. The gradient profile for solvent B was as follows: $2-40 \%$ in $120 \mathrm{~min}$, $95 \%$ in 10 $\mathrm{min}$, at $200 \mathrm{nl} / \mathrm{min}$. LC-MS/MS analysis of each digested fraction was conducted in duplicate. The experiment described above was repeated twice.

\section{Data analysis}

Raw LC-ESI data was converted to the various peak list files by NanoFrontier L Data Processing (Hitachi HighTechnologies). The peak list files were subsequently applied to MASCOT MS/MS ion search (version: 2.3.01) and X! Tandem http://www.thegpm.org software for protein identification. Upon peptide sequence 
annotation, the SwissProt database (version: 2010_08) of Homo sapiens (human) was used, with the following parameters: enzyme, trypsin; maximum number of missed cleavages, 1 ; peptide tolerance, $0.2 \mathrm{Da}$; MS/MS tolerance, $0.2 \mathrm{Da}$; variable modification, oxidation of methionine and protein $\mathrm{N}$ terminus acetylation; and peptide charge, $(1+, 2+$, and $3+)$. All identified proteins with MASCOT threshold scores lower than the $95 \%$ confidence level and peptide numbers lower than 2 were then removed from the protein list by using Scaffold software (Proteome Software, Portland, OR). Proteins found in both duplicate experiments were counted as the identified proteins.

\section{Results}

\section{Evaluation of HIAR using micro-sized chamber}

To evaluate the feasibility of HIAR using the microsized chamber, we compared the number of identified proteins under each sample condition (Figure 3A). The number of proteins identified from FFPE tissues was increased by HIAR compared to that under non-retrieval conditions. No difference in the number of identified proteins was observed between HIAR with or without the micro-sized chamber. These results suggested that protein identification was not influenced by the size of the chamber used for antigen retrieval.

The presence of proteins eluted from FFPE samples was confirmed by MS/MS analysis of the trypsinized supernatants. We identified 62 and 45 proteins in the supernatants after HIAR at $90^{\circ} \mathrm{C}$ and $110^{\circ} \mathrm{C}$, respectively (Figure 3B). In contrast, very few proteins $\left(1\right.$ and 5 proteins at $90^{\circ} \mathrm{C}$ and $110^{\circ} \mathrm{C}$, respectively) were detected in the supernatants obtained without the micro-sized chamber. These results indicated that the use of the micro-sized chamber enhanced protein identification from supernatants.

After HIAR at $110^{\circ} \mathrm{C}$ by using the micro-sized chamber, a minor leak was observed around the chamber (data not shown). To investigate the cause of the supernatant leak, we measured the volume of recovered supernatant under each retrieval condition without the FFPE sample fixed on the glass slide (Figure 4). A significant decrease in the volume of recovered supernatant was observed at $110^{\circ} \mathrm{C}$. On the basis of these results, the HIAR temperature for subsequent experiments was set at $90^{\circ} \mathrm{C}$.

To evaluate the efficiency of protein extraction in antigen retrieval with micro-sized chambers, we performed repetitive HIAR treatment against the tissues fixed on the glass slide (Additional file 1: Figure S1). The proportion of proteins identified from the supernatant in repeating treatments was decreased compared to that from the initial HIAR. Nearly all of the eluted proteins in the 2nd-4th HIAR were identical to the proteins identified from the initial HIAR. When identifying proteins from tissues, no significant difference was observed

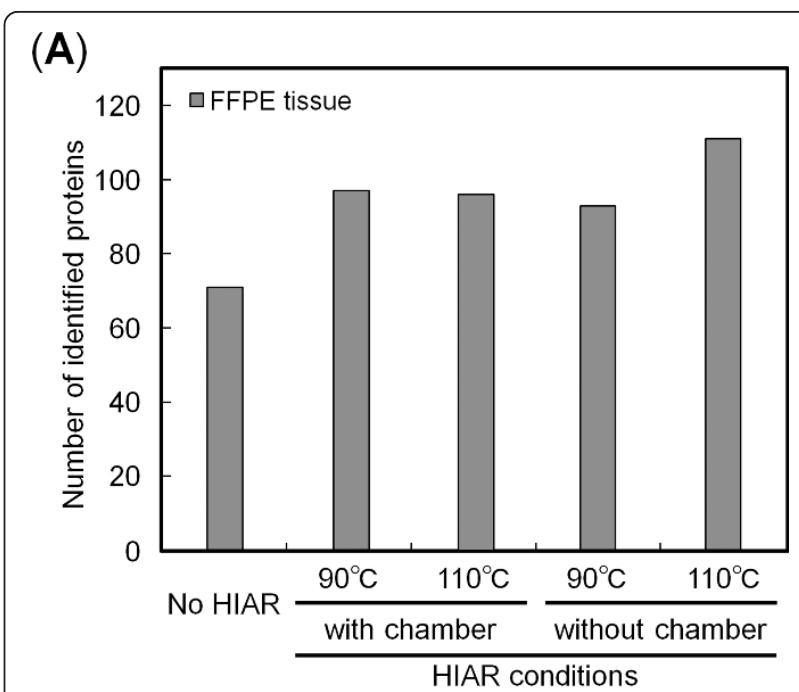

(B)

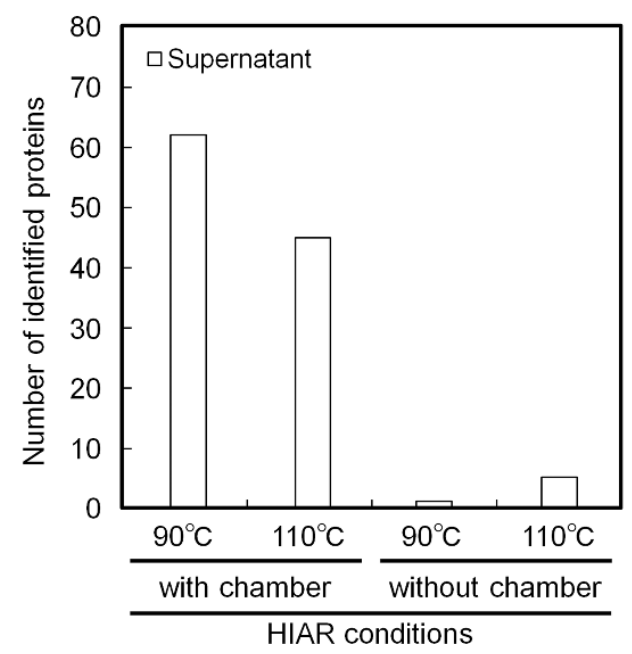

Figure 3 Number of identified proteins in (A) FFPE samples and (B) supernatants. FFPE samples underwent HIAR with and without micro-sized chamber in antigen-retrieval buffer at $90^{\circ} \mathrm{C}$ or $110^{\circ} \mathrm{C}$. The number of identified proteins in the trypsinized FFPE sample without HIAR was defined as No HIAR.

between the first and the final HIAR treatments. The results indicated that complete protein extraction and antigen retrieval were achieved using single HIAR with a micro-sized chamber.

We concluded that our HIAR treatment using the micro-sized chamber allowed protein identification separately in the supernatant and the FFPE samples fixed on the glass slide.

\section{Characterization of proteins eluted from the FFPE samples}

The combined proteomic results obtained from 3 samples of different tissues (FFPE tissue sections with and without retrieval, and the eluted supernatant) yielded a 


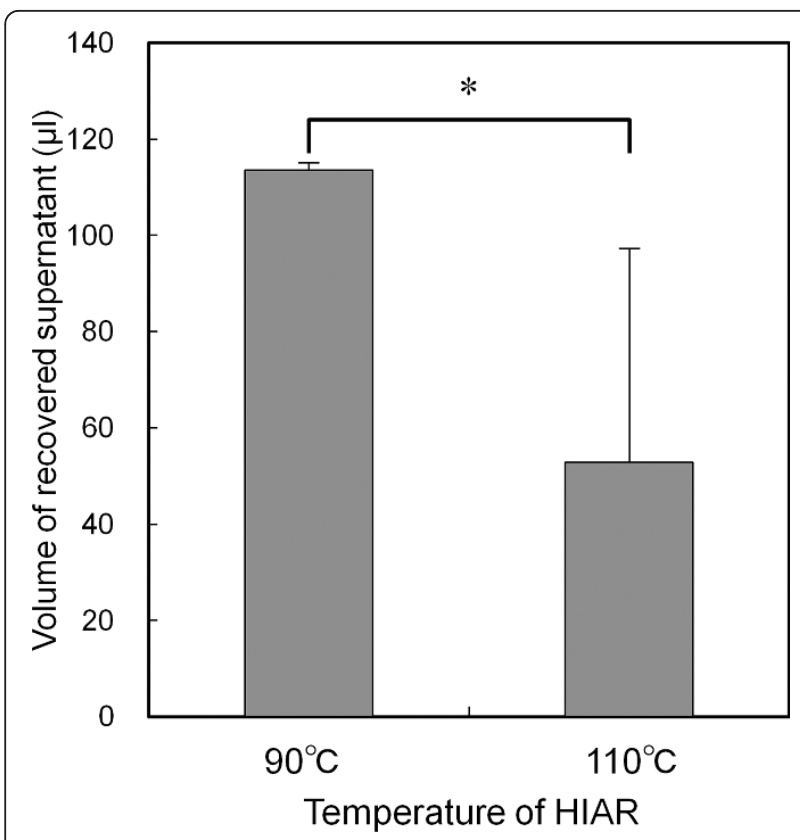

Figure 4 Amount of supernatant recovered from micro-sized chamber after HIAR. A total of $120 \mu$ of antigen-retrieval buffer was sealed in the micro-sized chamber. After HIAR, the volume of collected buffer was determined by weight. Data are expressed as mean value \pm SD $(n=6)$. Statistical significance $(* P<0.01)$ was evaluated by Student's $t$ test.

total of 142 distinct proteins. These unique proteins are listed in Additional file 2: Table S1. The Venn diagram in Figure 5A shows that $20.4 \%$ of the identified proteins were supernatant-specific. Among the 69 proteins identified in the supernatant, 40 proteins were identified in more than one sample. Our analysis required the identification of at least 2 distinct peptides to define a protein hit. Additionally, the proteins identified in only a single experiment were removed from the protein list. Therefore, our results indicated that the unique proteins found in the supernatant were consistently eluted by HIAR treatment from FFPE samples fixed on the glass slide.

Figure 5B shows a pseudo 2-D polyacrylamide gel electrophoresis (PAGE) display of 75 proteins identified in the 3 samples but not shared among them. The figure illustrates the distribution of protein properties, comparing $\mathrm{p} I$, molecular weight (MW), and estimated protein content (calculated using the exponentially modified protein abundance index, emPAI) $[24,25]$. The distribution of proteins identified in the supernatant was shifted toward a lower $\mathrm{p} I$ and $\mathrm{MW}$. The results suggest that our HIAR approach using micro-sized chambers preferentially promotes elution of low-MW proteins that tend to have a negative charge in the retrieval buffer. Further, the grand average of hydropathy (GRAVY) value [26] of the identified proteins was used to investigate the distribution of hydrophilic proteins (Figure 5C). Most proteins detected in the 3 samples had a negative GRAVY value, suggesting that the identified proteins tended to be hydrophilic. No significant difference was observed between the GRAVY values of the retrieved sample and the supernatant.

Sprung et al. [9] and Azimzadeh et al. [11] observed a preferential detection of peptides with C-terminal arginine over lysine in proteomic analyses of FFPE tryptic digests. We compared the log-transformed ratios of lysine-to-arginine-terminal peptides between the supernatant and the FFPE samples fixed on the glass slide (Figure 5D). A positive log-transformed ratio was observed only in the supernatant. This observed ratio was similar to that previously reported in frozen samples [9]. In contrast, the ratio in FFPE samples with and without HIAR treatment was negative.

\section{Discussion}

Shotgun proteome analyses of FFPE tissue specimens offer the prospect of retrospective biomarker discovery. In these analyses, HIAR treatment is one of the most important techniques for improving protein identification [1,4-12]. Facilitation of the accessibility of trypsin to proteins in FFPE samples via HIAR increases MS-detectable peptides $[6,20]$. Recently, Chu et al. developed a method for extracting proteins and nucleic acids directly from a fixed section, without destroying tissue morphology, using heat [21]. Their work raised the possibility that HIAR-treated FFPE samples fixed on the substrate may release and lose characteristic sets of proteins depending on the antigen-retrieval buffer. To demonstrate such selective elution, it is desirable to compare protein fragments between the FFPE sample and the buffer (superna$\operatorname{tant)}$ after HIAR. To that end, we used a strategy that enabled us to separately collect the supernatant containing MS-detectable peptides and antigen-retrieved FFPE tissues for the identification of eluted proteins.

HIAR for MS analysis has employed various buffers for improving protein identification in FFPE tissues, and these correspond to a variety of conditions for trypsinization and peptide extraction [4-6,8,12]. Many HIAR protocols use an acidic antigen-retrieval buffer followed by buffer exchange and/or washing (including rinsing the tissue) for trypsinization after HIAR. To efficiently trypsinize the retrieved FFPE sample without these additional steps, the use of a basic antigen-retrieval buffer is necessary. The optimal $\mathrm{pH}$ range for trypsinization is $\mathrm{pH}$ 7-9 [27]. In this study, FFPE tissues fixed on a glass slide were directly treated by HIAR, and then separated from the supernatant without washing. This approach for antigen retrieval is similar to preparation for MS imaging of FFPE tissue, in which HIAR is carried out in basic buffers without washing before trypsinization $[6,8]$. Moreover, 
(A)

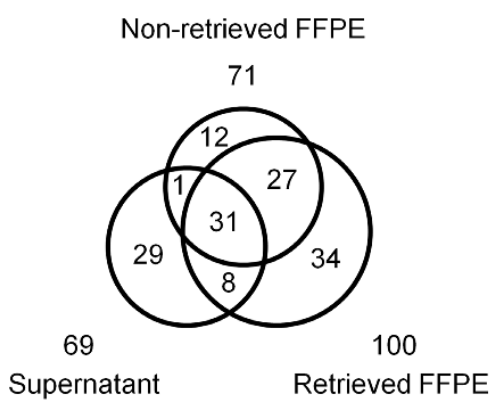

(C)

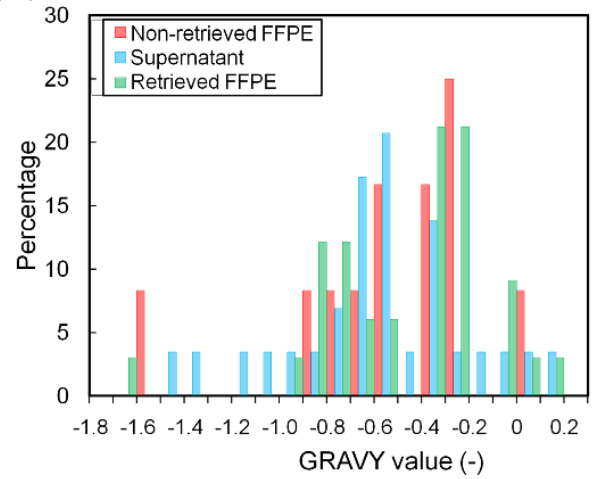

(B)

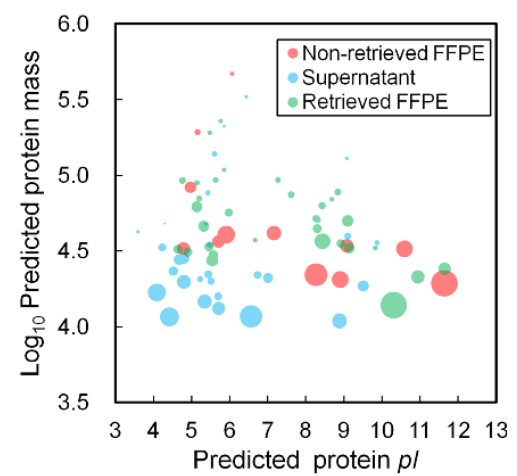

(D)

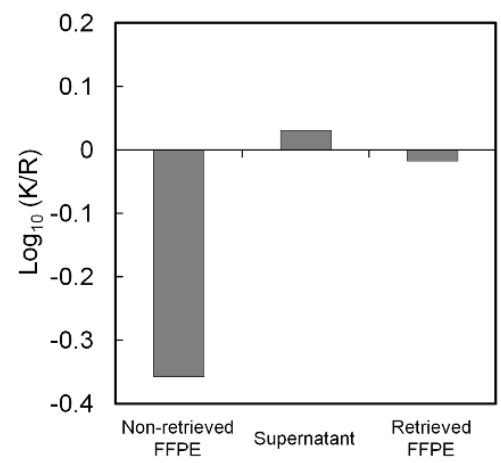

Figure 5 Characterization of the proteins identified in the non-retrieved and retrieved FFPE sample and the supernatant. (A) Venn diagram comparing the number of proteins identified in the above 3 samples. (B) A pseudo 2-D PAGE display of unshared proteins presented in Panel A (size of circle represents the emPAl-determined degree of protein abundance) $[24,25]$. (C) Distribution of the grand average of hydropathy (GRAVY) values of the unshared proteins identified in the above 3 samples. (D) Comparison of the log-transformed ratios of Cterminal lysine versus arginine peptides.

addition of $n$-octyl- $\beta$-D-glucoside improves the recovery rate of peptides [28]. Accordingly, we adopted a basic detergent-containing buffer optimized for HIAR of FFPE samples.

To increase efficiency of protein identification in the supernatant, we affixed a micro-sized chamber onto the FFPE samples fixed on the glass slide. The use of the micro-sized chamber significantly reduced the volume of the antigen-retrieval buffer. The small amount of supernatant collected from the micro-sized chamber was concentrated by centrifugal evaporation and trypsinized into one tube. In proteome analysis by MS, reduced handling of protein lysate by use of a single tube increases the efficiency of protein identification [29]. Therefore, our approach is likely to consistently enhance protein identification from the supernatant.

The new approach permitted us to compare the proteins that eluted into the supernatant with those that remained in FFPE tissues. We found that the proportion of low- $\mathrm{P} I$ and low-MW proteins was notably higher in the supernatant than in the retrieved and non-retrieved FFPE samples, as shown in the pseudo 2-D PAGE display. Our antigenretrieval buffer was basic ( $\mathrm{pH} 10)$, resulting in an increase in the negative charge density in the low-p $I$ proteins. Negatively charged proteins are thought to be denatured by heating in the macromolecular network structures of the FFPE tissue section $[18,30]$. Thus, we assume that the denatured low-p $I$ and low-MW proteins were preferentially eluted from the network structures into the supernatant under the HIAR conditions used in our study. These findings may indicate that HIAR from FFPE samples fixed on the substrate (e.g., when prepared for MS imaging) facilitates preferential elution of proteins determined by the properties of antigen-retrieval buffers.

The characterized proteins in the pseudo 2-D PAGE display tended to have hydrophilic properties as indicated by the GRAVY value (Figure 5C). No relationship was found between the hydrophilic properties of the proteins and their elution from the FFPE sample. To further investigate the presence of hydrophobic proteins, we mapped transmembrane (TM) domains by using the TM hidden Markov model (TMHMM) algorithm on the website http://www.cbs.dtu.dk/services/TMHMM/[31,32]. Proteins in which TM domains were identified by TMHMM were defined as hydrophobic [33]. Five proteins identified in the FFPE samples, but not in the 
supernatant, had a theoretical TM domain (see Additional file 2: Table S1), suggesting that TM domain-containing hydrophobic proteins were not eluted into the supernatant by HIAR. Thus, the presence of TM domains in a protein may promote resistance to protein elution from FFPE tissue.

Our HIAR approach showed the disproportionate loss of C-terminal lysine peptides in FFPE samples, consistent with previous results $[9,11]$. Surprisingly, in the peptides identified in the supernatant, this phenomenon was not observed. In agreement with previous findings [34-37], potential variable methylol $(+30 \mathrm{Da})$ and imine $(+12 \mathrm{Da})$ modifications among all samples did not yield any additional peptides that could be verified through manual spectral evaluation. This result suggested that these modifications were not involved in the shift of the $\mathrm{K}$ to $\mathrm{R}$ ratio. Therefore, the $\mathrm{K}$ to $\mathrm{R}$ ratio in the supernatant may indicate that no chemically modified protein fragments were preferentially released from FFPE samples by HIAR.

\section{Conclusion}

Our study describes a new HIAR method with a microsized chamber that can efficiently detect and identify proteins eluted from FFPE tissue sections. To our knowledge, this is the first time that a micro-sized chamber has been used to identify and characterize proteins from antigenretrieved FFPE samples. Using this technique, we show that specific proteins were preferentially released from FFPE samples, an outcome not observed previously by using HIAR.

\section{Additional material}

Additional file 1: Figure S1. Relative amount of proteins identified after repetitive HIAR treatments. The graph shows the relative amount of proteins identified after successive rounds of HIAR treatment in a microsized chamber.

Additional file 2: Table S1. List of all identified proteins. The file lists all proteins identified in the FFPE tissues with and without HIAR and in the supernatant

\section{Acknowledgements}

This research was partially supported by the Ministry of Education, Science, Sports and Culture, grant-in-cooperation of the Regional Innovation Cluster Program 2010, and Grant-in-Aid for Young Scientists (B), 23701092, 2011.

\footnotetext{
Author details

${ }^{1}$ Medical Genetics Division, Shizuoka Cancer Center Research Institute, 1007 Shimonagakubo, Nagaizumi-cho, Sunto-gun, Shizuoka 411-8777, Japan. ${ }^{2}$ Life Science Research Center, Shimadzu Corporation, 1 Nishinokyo-Kuwabara-cho, Nakagyo-ku, Kyoto 604-8511, Japan. ${ }^{3}$ Frontier Research Center, Tokyo Institute of Technology, 4259-B102 Nagatsuta-cho, Midori-ku, Yokohama 2268051, Japan. ${ }^{4}$ Shizuoka Cancer Center Hospital and Research Institute, 1007 Shimonagakubo, Nagaizumi-cho, Sunto-gun, Shizuoka 411-8777, Japan. ${ }^{5}$ Pathology Division, Shizuoka Cancer Center Hospital, 1007 Shimonagakubo, Nagaizumi-cho, Sunto-gun, Shizuoka 411-8777, Japan.
}

\section{Authors' contributions}

$\mathrm{KH}$ carried out proteomics experiments, data analysis, and figure preparation. $\mathrm{TN}$ and $\mathrm{H}$ conducted sample preparation and evaluated pathological specimens. SO and $\mathrm{KH}$ carried out protocol development. KY and TM provided reagents, materials, and analysis tools. KWN, YA, TS, and TM were scientific leads and participated in the design of the study. KWN and $\mathrm{KH}$ wrote the manuscript. All authors read and approved the final manuscript.

\section{Competing interests}

The authors declare that they have no competing interests.

Received: 16 February 2012 Accepted: 23 March 2012

Published: 23 March 2012

\section{References}

1. Prieto DA, Hood BL, Darfler MM, Guiel TG, Lucas DA, Conrads TP, Veenstra TD, Krizman DB: Liquid Tissue: proteomic profiling of formalinfixed tissues. Biotechniques 2005, 38:S32-S35.

2. Palmer-Toy DE, Krastins B, Sarracino DA, Nadol JB Jr, Merchant SN: Efficient method for the proteomic analysis of fixed and embedded tissues. $J$ Proteome Res 2005, 4:2404-2411.

3. Crockett DK, Lin Z, Vaughn CP, Lim MS, Elenitoba-Johnson KS: Identification of proteins from formalin-fixed paraffin-embedded cells by LC-MS/MS. Lab Invest 2005, 85:1405-1415.

4. Hood BL, Darfler MM, Guiel TG, Furusato B, Lucas DA, Ringeisen BR, Sesterhenn IA, Conrads TP, Veenstra TD, Krizman DB: Proteomic analysis of formalin-fixed prostate cancer tissue. Mol Cell Proteomics 2005 4:1741-1753.

5. Jiang X, Feng S, Tian R, Ye M, Zou H: Development of efficient protein extraction methods for shotgun proteome analysis of formalin-fixed tissues. J Proteome Res 2007, 6:1038-1047.

6. Ronci M, Bonanno E, Colantoni A, Pieroni L, Di llio C, Spagnoli LG, Federici G, Urbani A: Protein unlocking procedures of formalin-fixed paraffin-embedded tissues: application to MALDI-TOF imaging MS investigations. Proteomics 2008, 8:3702-3714.

7. Xu H, Yang L, Wang W, Shi SR, Liu C, Liu Y, Fang X, Taylor CR, Lee CS, Balgley BM: Antigen retrieval for proteomic characterization of formalinfixed and paraffin-embedded tissues. J Proteome Res 2008, 7:1098-1108.

8. Groseclose MR, Massion PP, Chaurand P, Caprioli RM: High-throughput proteomic analysis of formalin-fixed paraffin-embedded tissue microarrays using MALDI imaging mass spectrometry. Proteomics 2008, 8:3715-3724

9. Sprung RW Jr, Brock JW, Tanksley JP, Li M, Washington MK, Slebos RJ, Liebler DC: Equivalence of protein inventories obtained from formalinfixed paraffin-embedded and frozen tissue in multidimensional liquid chromatography-tandem mass spectrometry shotgun proteomic analysis. Mol Cell Proteomics 2009, 8:1988-1998.

10. Djidja MC, Claude E, Snel MF, Scriven P, Francese S, Carolan V, Clench MR: MALDI-ion mobility separation-mass spectrometry imaging of glucoseregulated protein $78 \mathrm{kDa}$ (Grp78) in human formalin-fixed, paraffinembedded pancreatic adenocarcinoma tissue sections. J Proteome Res 2009, 8:4876-4884

11. Azimzadeh O, Barjaktarovic Z, Aubele M, Calzada-Wack J, Sarioglu H, Atkinson MJ, Tapio S: Formalin-fixed paraffin-embedded (FFPE) proteome analysis using gel-free and gel-based proteomics. J Proteome Res 2010, 9:4710-4720

12. Nirmalan NJ, Hughes C, Peng J, McKenna T, Langridge J, Cairns DA, Harnden P, Selby PJ, Banks RE: Initial development and validation of a novel extraction method for quantitative mining of the formalin-fixed, paraffin-embedded tissue proteome for biomarker investigations. J Proteome Res 2011, 10:896-906.

13. Guo T, Wang W, Rudnick PA, Song T, Li J, Zhuang Z, Weil RJ, DeVoe DL, Lee CS, Balgley BM: Proteome analysis of microdissected formalin-fixed and paraffin-embedded tissue specimens. J Histochem Cytochem 2007, 55:763-772.

14. Scicchitano MS, Dalmas DA, Boyce RW, Thomas HC, Frazier KS: Protein extraction of formalin-fixed, paraffin-embedded tissue enables robust proteomic profiles by mass spectrometry. J Histochem Cytochem 2009, 57:849-860. 
15. Addis MF, Tanca A, Pagnozzi D, Crobu S, Fanciulli G, Cossu-Rocca P, Uzzau S: Generation of high-quality protein extracts from formalin-fixed, paraffin-embedded tissues. Proteomics 2009, 9:3815-3823.

16. Shi SR, Key ME, Kalra KL: Antigen retrieval in formalin-fixed, paraffinembedded tissues: an enhancement method for immunohistochemical staining based on microwave oven heating of tissue sections. J Histochem Cytochem 1991, 39:741-748.

17. Shi SR, Chaiwun B, Young L, Cote RJ, Taylor CR: Antigen retrieval technique utilizing citrate buffer or urea solution for immunohistochemical demonstration of androgen receptor in formalinfixed paraffin sections. J Histochem Cytochem 1993, 41:1599-1604.

18. Emoto K, Yamashita S, Okada Y: Mechanisms of heat-induced antigen retrieval: does $\mathrm{pH}$ or ionic strength of the solution play a role for refolding antigens? J Histochem Cytochem 2005, 53:1311-1321.

19. Wisztorski M, Franck J, Salzet M, Fournier I: MALDI direct analysis and imaging of frozen versus FFPE tissues: what strategy for which sample? Methods Mol Biol 2010, 656:303-322.

20. Gustafsson JO, Oehler MK, McColl SR, Hoffmann P: Citric acid antigen retrieval (CAAR) for tryptic peptide imaging directly on archived formalin-fixed paraffin-embedded tissue. J Proteome Res 2010, 9:4315-4328

21. Chu WS, Liang Q, Liu J, Wei MQ, Winters M, Liotta L, Sandberg G, Gong M: A nondestructive molecule extraction method allowing morphological and molecular analyses using a single tissue section. Lab Invest 2005, 85:1416-1428

22. Ogura SI, Kaneko K, Miyajima S, Ohshima K, Yamaguchi K, Mochizuki T: Proneurotensin/neuromedin $\mathrm{N}$ secreted from small cell lung carcinoma cell lines as a potential tumor marker. Proteom Clin Appl 2008, 2:1620-1627.

23. Hatakeyama K, Ohshima K, Fukuda Y, Ogura SI, Terashima M, Yamaguchi K, Mochizuki T: Identification of a novel protein isoform derived from cancer-related splicing variants using combined analysis of transcriptome and proteome. Proteomics 2011, 11:2275-2282.

24. Ishihama Y, Oda Y, Tabata T, Sato T, Nagasu T, Rappsilber J, Mann M: Exponentially modified protein abundance index (emPAl) for estimation of absolute protein amount in proteomics by the number of sequenced peptides per protein. Mol Cell Proteomics 2005, 4:1265-1272.

25. Shinoda K, Tomita M, Ishihama Y: emPAI Calc-for the estimation of protein abundance from large-scale identification data by liquid chromatography-tandem mass spectrometry. Bioinformatics 2010, 26:576-577.

26. Kyte J, Doolittle RF: A simple method for displaying the hydropathic character of a protein. J Mol Biol 1982, 157:105-132.

27. Sipos T, Merkel JR: An effect of calcium ions on the activity, heat stability, and structure of trypsin. Biochemistry 1970, 9:2766-2775.

28. Katayama H, Nagasu T, Oda Y: Improvement of in-gel digestion protocol for peptide mass fingerprinting by matrix-assisted laser desorption/ ionization time-of-flight mass spectrometry. Rapid Commun Mass Spectrom 2001, 15:1416-1421.

29. Wang N, Xu M, Wang P, Li L: Development of mass spectrometry-based shotgun method for proteome analysis of 500 to 5000 cancer cells. Anal Chem 2010, 82:2262-2271.

30. Yamashita S: Heat-induced antigen retrieval: mechanisms and application to histochemistry. Prog Histochem Cytochem 2007, 41:141-200.

31. Krogh A, Larsson B, von Heijne G, Sonnhammer EL: Predicting transmembrane protein topology with a hidden Markov model: application to complete genomes. J Mol Biol 2001, 305:567-580.

32. Cutillas PR, Biber J, Marks J, Jacob R, Stieger B, Cramer R, Waterfield M, Burlingame AL, Unwin RJ: Proteomic analysis of plasma membrane vesicles isolated from the rat renal cortex. Proteomics 2005, 5:101-112.

33. Masuda T, Tomita M, Ishihama Y: Phase transfer surfactant-aided trypsin digestion for membrane proteome analysis. J Proteome Res 2008, 7:731-740

34. Fowler CB, Cunningham RE, O'Leary TJ, Mason JT: 'Tissue surrogates' as a model for archival formalin-fixed paraffin-embedded tissues. Lab Invest 2007, 87:836-846.

35. Nirmalan NJ, Harnden P, Selby PJ, Banks RE: Mining the archival formalinfixed paraffin-embedded tissue proteome: opportunities and challenges. Mol Biosyst 2008, 4:712-720.

36. Metz B, Kersten GF, Hoogerhout P, Brugghe HF, Timmermans HA, de Jong $A$, Meiring $H$, ten Hove J, Hennink WE, Crommelin DJ, Jiskoot W:
Identification of formaldehyde-induced modifications in proteins: reactions with model peptides. J Biol Chem 2004, 279:6235-6243.

37. Metz B, Kersten GFA, Baart GJE, de Jong A, Meiring $H$, ten Hove J, van Steenbergen M, Hennink W, Crommelin DJA, Jiskoot W: Identification of formaldehyde-induced modifications in proteins: reactions with insulin. Bioconjug Chem 2006, 17:815-822.

doi:10.1186/1477-5956-10-19

Cite this article as: Hatakeyama et al:: Novel protein extraction approach using micro-sized chamber for evaluation of proteins eluted from formalin-fixed paraffin-embedded tissue sections. Proteome Science 2012 10:19.

\section{Submit your next manuscript to BioMed Central and take full advantage of:}

- Convenient online submission

- Thorough peer review

- No space constraints or color figure charges

- Immediate publication on acceptance

- Inclusion in PubMed, CAS, Scopus and Google Scholar

- Research which is freely available for redistribution 